\title{
Incidence of newborn screening disorders among 56632 infants in Central Saudi Arabia
}

\author{
A 6-year study
}

Sarar Mohamed, FRCPCH, MD, Wafa Elsheikh, MRCPCH UK, Aida I. Al-Aqeel, FRCP, FACMG, Amal M. Alhashem, MD, FMG, Ali Alodaib, PhD, Lujane Alahaideb, MSc, Maher Almashary, FACHRZT (Germany), Fahad Alharbi, PhD, Horia AlMalawi, MD, Amer Ammari, MD, Sulaiman Almohaimeed, MD, FRCP.

\begin{abstract}

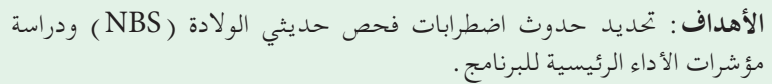

المنهجية : أجريت هذه دراسة بأثر رجعي أحادية المركز لجميع الأطفال المسجلين

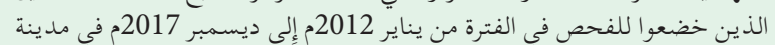

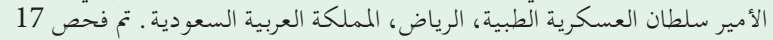

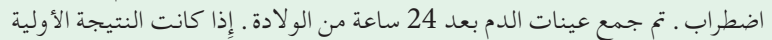

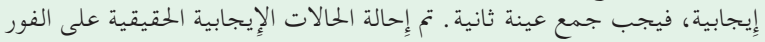

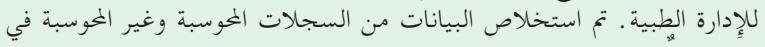

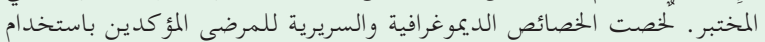
نماذج تقرير الحالة.

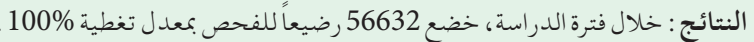

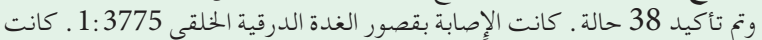

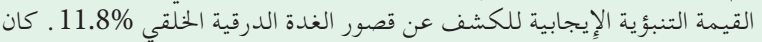

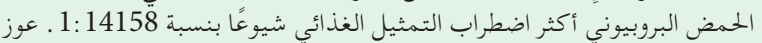
Acyl CoA Dehydrogenase

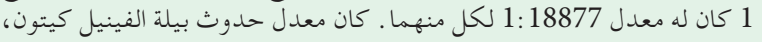

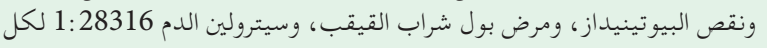

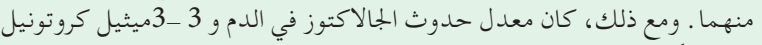

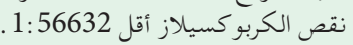

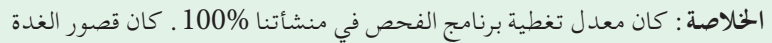

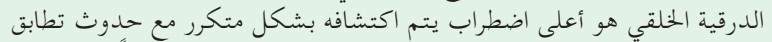

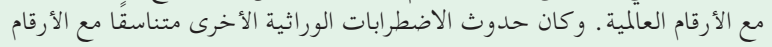

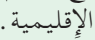

Objectives: To determine the incidence of newborn screening (NBS) disorders and to study the key performance indicators of the program.

Methods: This retrospective single-center study enrolled all infants who underwent NBS from January 2012 to December 2017 at Prince Sultan Military Medical City, Riyadh, Saudi Arabia. We screened 17 NBS disorders. Blood samples were collected 24 hours after birth. If the initial result was positive, a second sample was collected. True positive cases were immediately referred for medical management. Data were extracted from laboratory computerized and non-computerized records using case report forms.

Results: During the study period, 56632 infants underwent NBS with a coverage rate of $100 \%$. Thirtyeight cases were confirmed. The incidence of congenital hypothyroidism was $1: 3775$. The positive predictive value for the detection of congenital hypothyroidism was $11.8 \%$. Propionic aciduria was the most common metabolic disorder, with an incidence of 1:14158. Very long-chain acyl CoA dehydrogenase deficiency and glutaric aciduria type 1 had an incidence of 1:18877 each. Phenylketonuria, biotinidase deficiency, maple syrup urine disease, and citrullinemia had an incidence of 1:28316 each. However, galactosemia and 3-methyl crotonyl carboxylase deficiency had the lowest incidence of $1: 56632$.

Conclusion: The NBS coverage rate at our facility was $100 \%$. Congenital hypothyroidism was the most frequently detected disorder with an incidence that matches worldwide figures. The incidence of other inherited disorders was consistent with regional figures.

Keywords: incidence, newborn, Saudi Arabia, screening

Saudi Med J 2020; Vol. 41 (7): 703-708 doi: 10.15537/smj.2020.7.25147

From the Department of Pediatrics (Mohamed, Elsheikh, Al-Aqeel, Alhashem, AlMawlawi, Ammari, AlMohaimeed), from the Newborn Screening Laboratory (Alharbi), Prince Sultan Military Medical City; from the Prince Abdullah bin Khaled Celiac Disease Research Chair (Mohamed), King Saud University; from the Department of Pediatrics (Mohamed), from the Department of Cell Biology (Al-Aqeel, Alhashem), Alfaisal University; from the King Salman Center for Disability Research (Alodaib, Alahaideb); and from the Newborn Screening Program (Almashary, AlMohaimeed), Medical Service Directorate, Ministry of Defense, Riyadh, Kingdom of Saudi Arabia.

Received 8th April 2020. Accepted 4th June 2020.

Address correspondence and reprint request to: Prof. Sarar Mohamed, Department of Pediatrics, Prince Sultan Military Medical City, Riyadh, Kingdom of Saudi Arabia. E-mail: srarmohamed@psmmc.med.sa ORCID ID: https://0000-0002-7393-5064 
$\mathrm{N}$ ewborn screening (NBS) is a search for diseases in newborn infants before signs and symptoms appear. ${ }^{1}$ The aim of NBS is to identify affected babies and intervene to prevent associated morbidity and mortality. Implementing NBS program is subject to local resources and healthcare infrastructure. Worldwide, there are wide variations in the number of screened disorders ranging from one in some countries to 50 in other countries. ${ }^{1,2}$ In China, NBS began in 1981 with 2 disorders, which were congenital hypothyroidism $(\mathrm{CH})$ and phenylketonuria (PKU), before it expanded. ${ }^{2}$ In Canada, NBS for $\mathrm{CH}$ started as a pilot project in 1974, and then it became universal, including all newborns. ${ }^{2,3}$ The NBS Program in Western Europe, North America, and Australia adopt different strategies and screen for different disorders. ${ }^{1,2}$ Congenital hypothyroidism is one of the top causes of mental retardation, and it is completely preventable. ${ }^{3}$ Congenital hypothyroidism can either be permanent in the form of dysgenesis, agenesis, or dyshormonogenesis, or it can be transient. ${ }^{2,3}$ Neonatal thyroid function can also be transiently suppressed by the trans-placental passage of maternal medications, maternal blocking antibodies, or iodine deficiency or excess. ${ }^{3}$ Until the first half of pregnancy, the fetus is entirely dependent on maternal thyroid hormones that are transported through the placenta. ${ }^{3}$ The fetus then begins to function autonomously, starting at mid-gestation when the hypothalamic-pituitary axis is activated. Affected fetuses may appear normal at birth partly because of maternal thyroid hormones and partly because the brain converts $\mathrm{T} 4$ to $\mathrm{T} 3$, which confers protection. ${ }^{3}$ The current recommendation is to start treatment for $\mathrm{CH}$ within 2 weeks, making early screening of paramount importance. ${ }^{3,4}$ A variety of inborn errors of metabolism (IEM) fulfill the criteria for NBS and, therefore, were included in most of the screening programs. These include aminoacidopathies, organic aciduria, urea cycle defect, and fatty acid oxidation disorders. ${ }^{1,2,5}$ The choice of the disorders to be screened follows the WHO Wilson and Junger principles of screening and genetic testing. ${ }^{6}$ The NBS Program in the Kingdom of Saudi Arabia (KSA) was launched in 2005 as a collaboration between many Saudi health authorities, including King Faisal Specialist Hospital and Research Center (KFSH-RC), King Salman Center for Disability Research (KSCDR)

Disclosure. Authors have no conflict of interests, and the work was not supported or funded by any drug company. and the Ministry of Health. ${ }^{1,5}$ The ultimate goal was to achieve overall coverage of KSA within 10 years. ${ }^{1,5}$

Currently, over 200 hospitals that belong to different health sectors are involved (Ministry of Health, Ministry of National Guard, Ministry of Defense, and KFSH-RC). ${ }^{1,5}$ The Saudi national program screens for 17 metabolic disorders. However, 3 more disorders were proposed to be added in 2019, making a total of 20 disorders. ${ }^{1,5}$ The NBS program at Prince Sultan Military Medical City (PSMMC), Riyadh, was launched in November 2011 in collaboration with the King Salman Disability Center. ${ }^{1,5}$ There is a knowledge gap regarding the key performance indicators in the Saudi NBS program. ${ }^{5}$ Moreover, the incidence of $\mathrm{CH}$ reported from the national NBS program is not consistent with the international nor with the regional figures. ${ }^{5-14}$ Therefore, reviewing the NBS data from our center may add to the existing knowledge. The main objective of this study was to determine the incidence of all NBS disorders at PSMMC and to study the key performance indicators of NBS, which are the coverage, the turnaround time (TAT), and the sample rejection rate.

Methods. This is a retrospective study of all infants who underwent NBS from January 2012 to December 2017. A total of 56632 newborns were screened for 17 inborn errors of metabolism (Table 1) at PSMMC in Riyadh, Saudi Arabia. Prince Sultan Military Medical City is a tertiary military hospital that serves military personnel and their families. The birth rate at our facility is $10,000-12,000$ per year. All newborn infants who were born alive during the study period and have gestation age above or equal to 23 weeks were included in this study. Still birth, intrauterine fetal death and infants born before 23 weeks of gestation were excluded. Data were extracted from the laboratory computerized and non-computerized records in addition to the NBS database, which belongs to King Salman Disability Center, where the tests were performed. Demographic and clinical characteristics of confirmed patients were extracted using case report forms.

Blood samples were obtained from newborns 24 hours after birth by a heel prick where dried blood spots (DBS) are collected on a filter paper (Guthrie card). The amino acids and acylcarnitines were extracted and processed using a non-derivatized kit-based method (NeoBase-Perkin Elmer, Finland). The extracted amino acids and acylcarnitines were analyzed utilizing liquid chromatography-tandem mass spectrometer (LC-MS/ MS) using (AB Sciex-API 3200, USA). Positive mode electrospray ionization ion source (ESI) was 
used. Multiple reaction monitoring acquisition mode (MRM) was employed to identify and quantify different metabolites with the use of N2 as the collision gas.

A Genetic Screening Processor (GSP), Auto-DELFIA automatic immunoassay system, and VICTOR2 D semi-automatic DELFIA system were used to analyze thyroid-stimulating hormone (TSH), 17 hydroxyprogesterone (17-OHP), biotinidase and galactose 1 phosphate uridyl transferase (GALT) levels. ${ }^{1,5}$

Cut-off levels for each analyte were established based on data that were obtained from the previous studies. ${ }^{5}$ The initial normal results were reported as "not remarkable." However, any initial abnormal result was retested using the same DBS that was received. If the result remains abnormal, a recall sample (namely, a second sample) was requested. If the recall sample was normal, then the case was reported as "now not remarkable." If the result remains abnormal, a final abnormal screening report will be generated and sent immediately to the medical team to start the medical management plan. The diagnosis will be confirmed by conducting additional biochemical testing such as serum TSH, T4, plasma amino acid, and urine organic acids analysis. The cut-off values of biomarkers are shown in Table 1. All inherited disorders were confirmed by DNA studies.

Table 1 - The panel of screened disorders in Saudi Arabia.

\begin{tabular}{|c|c|c|c|}
\hline Category & Disorder & Biomarker & Cut-off level \\
\hline \multirow[t]{7}{*}{ Organic acid defects } & Glutaric aciduria type 1 & C5-carnitine & $\geq 1.53 \mu \mathrm{mol} / \mathrm{L}$ \\
\hline & Isovaleric aciduria (IVA) & C5-carnitine & $\geq 1.53 \mu \mathrm{mol} / \mathrm{L}$ \\
\hline & Methylmalonic aciduria (MMA) & $\begin{array}{l}\text { C3-carnitine } \\
\text { C3-/C2-carnitine }\end{array}$ & $\begin{array}{l}\geq 10 \mu \mathrm{mol} / \mathrm{L} \\
\text { ratio } \geq 0.4\end{array}$ \\
\hline & Propionic aciduria (PA) & $\begin{array}{l}\text { C3- carnitine } \\
\text { C3-/C2-carnitine }\end{array}$ & $\begin{array}{l}\geq 10 \mu \mathrm{mol} / \mathrm{L} \\
\text { ratio } \geq 0.4\end{array}$ \\
\hline & $\begin{array}{l}\text { 3-Methylcrotonyl-CoA carboxylase deficiency } \\
\text { (3-MCC) }\end{array}$ & C5-OH-carnitine & $\geq 0.8 \mu \mathrm{mol} / \mathrm{L}$ \\
\hline & Beta-Ketothiolase deficiency (BKT) & $\begin{array}{l}\text { C5-OH-carnitine } \\
\text { C5:1-carnitine }\end{array}$ & $\begin{array}{l}\geq 0.8 \mu \mathrm{mol} / \mathrm{L} \\
\geq 0.4 \mu \mathrm{mol} / \mathrm{L}\end{array}$ \\
\hline & HMG-CoA lyase deficiency & $\begin{array}{l}\text { C5-OH-carnitine } \\
\text { C6DC-carnitine }\end{array}$ & $\begin{array}{l}\geq 0.8 \mu \mathrm{mol} / \mathrm{L} \\
\geq 0.4 \mu \mathrm{mol} / \mathrm{L}\end{array}$ \\
\hline \multirow{5}{*}{$\begin{array}{l}\text { Inborn errors of amino acid } \\
\text { metabolism and } \\
\text { urea cycle defects }\end{array}$} & Phenylketonuria (PKU) & Phenylalanine Phenylalanine/tyrosine & $\begin{array}{l}\geq 180 \mu \mathrm{mol} / \mathrm{L} \\
\text { Ratio } \geq 3.1\end{array}$ \\
\hline & Maple syrup urine disease (MSUD) & $\begin{array}{l}\text { XLeu (leucine }(+ \text { isoleucine })) \\
\text { XLeu (leucine }(+ \text { isoleucine })) / \text { alanine }\end{array}$ & \\
\hline & & & $\geq 1.28$ \\
\hline & Arginosuccinate lyase deficiency (ASL) & $\begin{array}{l}\text { Argininosuccinic acid (daughter of ASA/ } \\
\text { daughter of C16-carnitine) }\end{array}$ & ratio $\geq 0.05$ \\
\hline & Citrullinemia (ASS) & Citrulline & $\geq 70 \mu \mathrm{mol} / \mathrm{L}$ \\
\hline \multirow[t]{2}{*}{ Fatty acid oxidation defects } & $\begin{array}{l}\text { Medium-chain acyl-CoA dehydrogenase } \\
\text { deficiency (MCAD) }\end{array}$ & $\begin{array}{l}\text { C6-carnitine } \\
\text { C8-carnitine } \\
\text { C8-/C2-carnitine } \\
\text { C8-/C10-carnitine }\end{array}$ & $\begin{array}{l}\geq 0.35 \mu \mathrm{mol} / \mathrm{L} \\
\geq 0.32 \mu \mathrm{mol} / \mathrm{L} \\
\text { ratio } \geq 0.1 \\
\text { ratio } \geq 1.6\end{array}$ \\
\hline & $\begin{array}{l}\text { Very long-chain acyl-CoA dehydrogenase } \\
\text { deficiency (VLCAD) }\end{array}$ & C14:1-carnitine, C14:1-/C16-carnitine & $\begin{array}{l}\geq 0.75 \mu \mathrm{mol} / \mathrm{L} \\
\text { ratio } \geq 0.30\end{array}$ \\
\hline $\begin{array}{l}\text { Inborn errors of } \\
\text { carbohydrates }\end{array}$ & Galactosemia & $\begin{array}{l}\text { GALT (galactose } 1 \text { phosphate uridyl } \\
\text { transferase) activity }\end{array}$ & $<3.5 \mathrm{U} / \mathrm{gHb}$ \\
\hline Vitamin responsive disorders & Biotinidase deficiency & Biotinidase activity & $<39.4 \mathrm{U} / \mathrm{dL}$ \\
\hline \multirow[t]{2}{*}{ Endocrinopathies } & Congenital hypothyroidism $(\mathrm{CH})$ & TSH (thyroid-stimulating hormone) & $\geq 21 \mu \mathrm{U} / \mathrm{mL}$ \\
\hline & Congenital adrenal hyperplasia $(\mathrm{CAH})$ & 17-OHP (17 hydroxyprogesterone) & $\geq 60 \mathrm{nmol} / \mathrm{L}$ \\
\hline \multirow{3}{*}{$\begin{array}{l}\text { New additions in January } \\
2019\end{array}$} & Tyrosinemia-I & Succinylacetone & $4.5 \mu \mathrm{mol} / \mathrm{L}$ \\
\hline & Homocystinuria: using & $\begin{array}{l}\text { Methionine } \\
\text { Methionine/Phenylalanine }\end{array}$ & $\begin{array}{l}75 \mu \mathrm{mol} / \mathrm{L} \\
\text { Ratio } 1\end{array}$ \\
\hline & Primary carnitine deficiency & Free carnitine $(\mathrm{C} 0)$ & $8 \mu \mathrm{mol} / \mathrm{L}$ \\
\hline
\end{tabular}


This study was approved by the Institutional Review Board of PSMMC.

Statistical analysis. Statistical analysis was performed using SPSS software, version 22.0, for Windows (SPSS, Inc., Chicago, IL, USA). Categorical variables were presented as frequencies and percentages, while continuous variables were presented as the mean and standard deviation. A $p$-value of $<0.05$ was regarded as statistically significant.

Results. A total of 56632 newborn infants were screened in this study. There were 38 truly positive cases, resulting in an overall incidence of 1:1490 for all screened disorders. Congenital hypothyroidism emerged as the leading disorder with an incidence of 1:3775. The highest incidence of IEM was seen in propionic aciduria, which had an incidence of 1:14158, while classic galactosemia had an incidence of 1:56632 (Table 2).

Out of 127 initially abnormal results for $\mathrm{CH}, 15$ were confirmed to be true cases, resulting in a positive predictive value of $11.8 \%$ (Table 3 ). The TAT was studied as a key performance indicator (KPI) and defined to be the time between receiving the sample and reporting its result. The TAT for confirmed $\mathrm{CH}$ was mean $\pm \mathrm{SD}$ : $2.5 \pm 1.168$ days (Table 3).

Similarly, the average time between the first abnormal result and $\mathrm{CH}$ confirmation was mean \pm SD: $3.3 \pm 1.939$ days (Table 4). The TAT for screened disorders other than $\mathrm{CH}$ was approximately 1-8 days

Table 2 - Incidence of screened disorders.

\begin{tabular}{lcc}
\hline Different disorders & $\begin{array}{c}\text { Number of } \\
\text { abnormal } \\
\text { disorders }\end{array}$ & Incidence \\
\hline Congenital hypothyroidism & 15 & $1: 3775$ \\
Phenylketonuria & 2 & $1: 28316$ \\
Biotinidase deficiency & 2 & $1: 28316$ \\
VLCAD & 3 & $1: 18877$ \\
citrullinemia & 2 & $1: 28316$ \\
Glutaric aciduria & 3 & $1: 18877$ \\
Propionic aciduria & 4 & $1: 14158$ \\
Methylmalonic aciduria & 3 & $1: 18877$ \\
Maple syrup urine disease & 2 & $1: 28316$ \\
3methyl crotonyl carboxylase deficiency & 1 & $1: 56632$ \\
Galactosemia & 1 & $1: 56632$ \\
Total & 38 & $1: 1490$ \\
\hline \multicolumn{2}{c}{ VLCAD: very-long-chain acyl CoA dehydrogenase deficiency } \\
\hline
\end{tabular}

(Table 5). Thyroid agenesis was found in $20 \%$ of the cases, $13.3 \%$ had an ectopic gland, $13.4 \%$ had thyroid hypoplasia, $6.7 \%$ thyroglossal cyst, while dyshormonogenesis was found in $20 \%$. These cases were confirmed using isotope scan or thyroid US. The mean cord TSH value was 516.125 (7-1159), and the mean FT4 was 10.158 (2.4-24).

Table 3 - Confirmed congenital hypothyroidism compared to the initial positive cases.

\begin{tabular}{cccc}
\hline Year & $\begin{array}{c}\text { Number of babies } \\
\text { screened }\end{array}$ & $\begin{array}{c}\text { Initial positive } \\
\text { cases with } \\
\text { hypothyroidism }\end{array}$ & $\begin{array}{c}\text { Confirmed } \\
\text { hypothyroidism }\end{array}$ \\
\hline 2012 & 9643 & 42 & $6(14.3)$ \\
2013 & 9405 & 46 & $3(6.5)$ \\
2014 & 9598 & 10 & $1(10.0)$ \\
2015 & 9152 & 11 & $2(18.2)$ \\
2016 & 8839 & 9 & $2(22.2)$ \\
2017 & 9995 & 9 & $1(11.1)$ \\
Total & 56632 & 127 & $15(11.8)$ \\
\hline
\end{tabular}

Table 4 - Turnaround time of the initial positive and confirmed congenital hypothyroidism $(\mathrm{CH})$.

\begin{tabular}{lcc}
\hline Period & $\begin{array}{c}\text { All suspected } \\
\mathrm{CH} \\
(\mathbf{n}=127)\end{array}$ & $\begin{array}{c}\text { Confirmed } \\
\mathrm{CH} \\
(\mathbf{n}=15)\end{array}$ \\
\hline $\begin{array}{c}\text { Sample receipt to the first report } \\
\text { Mean } \pm \text { SD (days) }\end{array}$ & $\begin{array}{c}3.02 \pm 1.305 \\
(1-7)\end{array}$ & $\begin{array}{c}2.50 \pm 1.168 \\
(2-6)\end{array}$ \\
Range (Minimum-Maximum) & & \\
First report to the second report & $4.76 \pm 4.701$ & $3.286 \pm 1.939$ \\
Mean \pm SD (days) & $(1-29)$ & $(1-8)$ \\
Range (Minimum-Maximum) & & \\
Repeat to confirmation & - & $1.66 \pm 3.5$ \\
Mean \pm SD (days) & & $(1-4)$ \\
Range (Minimum-Maximum) & & \\
\hline
\end{tabular}

Table 5 - Turnaround time for screened disorders other than congenital hypothyroidism.

\begin{tabular}{lcc}
\hline Period & $\begin{array}{c}\text { Screened disorders (N=23) } \\
\text { Mean } \pm \text { SD } \\
\text { (days) }\end{array}$ & $\begin{array}{c}\text { Range } \\
\text { (Minimum- } \\
\text { Maximum) }\end{array}$ \\
\hline Sample receipt to the first report & $5.8 \pm 3.46$ & $2-19$ \\
The first report to the second repeat & $2.95 \pm 1.75$ & $1-8$ \\
Sample receipt to confirmation & $2.17 \pm 2.12$ & $1-8$ \\
\hline
\end{tabular}


Table 6 - Rejected dry blood spot samples in the 56632 screened samples.

\begin{tabular}{lc}
\hline Total number of rejected samples & 36 \\
Rejection rate & $1: 1573$ \\
Year of birth & Number of rejected samples \\
2011 & 3 \\
2012 & 22 \\
2013 & 3 \\
2014 & 6 \\
2016 & 2 \\
2017 & 0 \\
\hline
\end{tabular}

All babies born at our hospital during the current study were screened, resulting in a coverage rate of $100 \%$. Only 36 initial samples were not satisfactory for testing, resulting in a rejection rate of 1:1573, with the highest in 2012 (Table 6).

Discussion. In this single-center retrospective study, we report the incidence of the 17 disorders that are included in the Saudi national NBS program. With an average rate of 10,000 deliveries per year, our institute is considered to be one of the highest birth rate facilities in Saudi Arabia. This allows a proper assessment of the efficiency of NBS program implementation. We found that the overall incidence of the screened disorders at PSMMC was 1:1490. For IEMs, propionic aciduria had the highest incidence (1:14158), while galactosemia had the lowest incidence (1:56632). These data were consistent with the national Saudi NBS figures that were reported by Alfadel et al ${ }^{5}$ As documented in previous studies that were conducted in Saudi Arabia, the incidence of IEM in the current study is almost 4 to 5 -fold higher than that reported by western screening programs., ${ }^{1,2,5}$ This could be explained by the high incidence of consanguinity in the Saudi community, which is as high as $56 \% .{ }^{5}$ Similarly, the incidence of IEM in regional countries such as Qatar $^{13}$ was reported to be $1: 1327$ and the United Arab Emirates ${ }^{14}$ was 1:1047. Similar to the Saudi community, other Arab countries share a high incidence of consanguinity, and therefore, this predisposes the people to a high incidence of mostly autosomal recessive IEMs. ${ }^{13,14}$

The incidence of $\mathrm{CH}$ in this study was $1: 3775$, which matches the worldwide incidence (1:3000 - 1:4000). This is consistent with the report by Al-Jurayyan et $\mathrm{al}_{1}{ }^{4}$ which showed that the incidence of $\mathrm{CH}$ in Saudi Arabia was 1:32924. However, Alfadhel et $\mathrm{al}^{1}$ who included 139 hospitals across the KSA, showed an incidence of
1:7175 for $\mathrm{CH}$. This low incidence does not match our findings, and it is not consistent with the regional and international figures. ${ }^{1-3,5,9,11,15}$ The low incidence of $\mathrm{CH}$ reported by Alfadel et $\mathrm{al}^{5}$ could be explained by the fact that the national NBS program receives samples from all over the KSA, which may lead to failure in securing second recall samples. Difficulties in getting the families back to the hospital after being discharged, especially those families who live outside Riyadh, may contribute to the low incidence of $\mathrm{CH}$ that was reported by the national NBS. ${ }^{5,15}$ Additionally, some hospitals that are participating in the national NBS may perform the confirmatory testing onsite without adding the results to the national registry. ${ }^{5,15}$ However, the data generated from the current study seem to be more accurate because the possibility of missing recall samples from a single center is less likely. Moreover, the incidence of $\mathrm{CH}$ that we report in this study matches the regional and international figures. $3,7,8,10,13,15,16$ Therefore, the incidence of $\mathrm{CH}$ in our study confirms the findings that were reported by Aljurayan et $\mathrm{al}^{4}$ who studied the first million Saudi babies who were screened for $\mathrm{CH}$, and they showed an incidence of 1:3292.

The TAT is one of the main key performance indicators of the NBS program. In this study, TAT, which includes the time from the sample receipt to generating the first and the final reports, matches the figures that were published by different NBS programs. ${ }^{1-3,8,12-15}$ Adhering to the recommended TAT alleviates parental stress that is caused by false-positive screening results, and it also accelerates the detecting of affected infants who require urgent management.

The other key performance indicators in this study, including the coverage and the sample rejection rate, match the figures that were reported by other international programs. ${ }^{3,-3,8,12-15}$ Because this was a single-center study, we were able to achieve these good results, and the systematic follow-up process offered by our facility contributed to this successful program.

Study limitations. This study is limited by being conducted at a single center, which may reflect different infrastructure and logistics compared to other institutes in the country. Therefore, our results should be interpreted with caution and may not be generalizable to other medical facilities in Saudi Arabia.

In conclusion, we reported the incidence of NBS disorders at our center and showed that the $\mathrm{CH}$ incidence was similar to the worldwide incidence. The incidence of IEM was comparable to the regional figures, but it was higher than the international incidence rates. The 
coverage rate of our screening program was $100 \%$, and the other key performance indicators were acceptable.

Acknowledgment. The authors would like to thank Prince Abdullah bin Khalid Celiac Disease Research chair, Vice Deanship of Scientific Research Chairs, King Saud University, Riyadh, Saudi Arabia, for their support. We would like to thank the American manuscript editors for English language editing.

\section{References}

1. Alfadhel M, Al Saif S, Al Zaben A. Manual of establishing a newborn screening program, diagnosis and management of screened disorders. Riyadh (KSA): King Fahad Library; 2016.

2. Shix T, Cai J, Wang YY, Tu WJ, Wang WP, Gong LM, Wang DW, Ye YT, Fang SG, Jing PW. Newborn screening for inborn errors of metabolism in mainland China: 30 years of experience. JIMD Rep 2012; 6: 79-83.

3. Maynika V Rastogi, Stephen H LaFranchi.Congenital hypothyroidism. Orphanet J Rare Dis 2010; 5: 17.

4. Al Jurayyan NA, Al-Nuaim AA, Redha MA et al. Neonatal Screening for Congenital Hypothyroidism in Riyadh: Analysis of Six Years' Experience. Ann Saudi Med 1996; 16: 20-23.

5. Alfadhel M, Al Othaim A, Al Saif S, Al Mutairi F, Alsayed M, Rahbeeni $Z$ et al. Expanded newborn screening program in Saudi Arabia: incidence of screened disorders. J Paediatr Child Health 2017; 53: 585-591.

6. Wilson JMG, Jungner G. Principles and practice of screening for disease. Geneva (SW): World Health Organization; 1968.

7. Lain S, Trump C, Grosse S, Olivieri A, Van Valiet G. Are lower TSH cutoffs in neonatal screening for congenital hypothyroidism warranted? Eur J Endocrinol 2017; 177: D1-D12.
8. Knowles RL, Oerton J, Cheetham T, Butter G, Cavanaqh C, Tetlow L, et al. Newborn screening for primary congenital hypothyroidism: estimating test performance at different TSH thresholds. J Clin Endocrinol Metab 2018; 103: 3720-3728.

9. Corbetta C, Weber G, Cortinouis F, Calebiro D, Passoni A, Beck Peccoz P, Chiumello G, Persanil. A 7 years' experience with low blood TSH cutoff levels for neonatal screening reveals an unsuspected frequency of congenital hypothyroidism. Clin Endocrinol $(O x f)$ 2009; 71: 739-745.

10. Saleh D, Lawrence S, Geraghty M, Gallego P, Assey K, wherrett D, Chakraborty P. Prediction of congenital hypothyroidism based on initial screening thyroid-stimulating hormone. $B M C$ Pediatr 2016; 16: 24.

11. Babiker A, Al Jurayyan N, Mohamed S, Abdullah MA. Overview of diagnosis, management and outcome of congenital hypothyroidism: A call for a national screening program in Sudan. Sudan J Paediatr 2012; 12: 7-16.

12. Marquardt G, Currier R, McHugh D, Gavrilov D, Magera MJ, Matern D, et al. Enhanced interpretation of newborn screening results without analyte cutoff values. Genet Med 2012; 14: 648-655.

13. Lindner M, Abdoh G, Fang-Hoffmann J, Shabeck N, Al-Sayrafi M, Al-Janahi M, et al. Implementation of extended neonatal screening and a metabolic unit in the State of Qatar: Developing and optimizing strategies in cooperation with the Neonatal Screening Center in Heidelberg. J Inherit Metab Dis 2007; 30: 522-529.

14. Al Hosani H, Salah M, Osman HM et al. Expanding the comprehensive national neonatal screening program in the United Arab Emirates from 1995 to 2011. East Mediterr Health J 2014; 20: 17-23.

15. Mohamed S. Reflection on the expanded newborn screening program in Saudi Arabia: Incidence of screened disorders. $J$ Paediatr Child Health 2017; 53: 1034-1035.

16. Al Aqeel AI. Expanded Newborn Screening Programme in Saudi Arabia: Are We Ready? J Paediatr Child Health 2017; 53: 1242 . 